\title{
Efficacy of Continuous Femoral Nerve Block with Stimulating Catheters Versus Nonstimulating Catheters - A Systematic-Narrative Review
}

\author{
Mario Dauri, Ludovica Celidonio, Sarit Nahmias, \\ Eleonora Fabbi, Filadelfo Coniglione and Maria Beatrice Silvi \\ Department of Anesthesia and Intensive Care Unit, Tor Vergata University, Rome, \\ Italy
}

\section{Introduction}

A femoral nerve block is simple to perform, has a high rate success, carries a low risk of complications, and it is widely used technique for surgical anesthesia and post-operative pain management of the lower extremity. It provides analgesia to the anterior thigh, including the flexor muscles of the hip and extensor muscles of the knee and therefore, it is well suited for surgeries that involve the hip, the knee or the anterior thigh zone. The femoral nerve block is often associated with sciatic nerve block in order to achieve a lower extremity analgesia.

The anterior approach to the femoral nerve block initially described as a 3-in-1 block by Winnie et al (Winnie et al., 1973), suggested that the femoral, lateral femoral cutaneous, and obturator nerves could be blocked from a single paravascular injection at a point inferior to the inguinal crease. Studies have since showed that the femoral can be reliably blocked by a single injection, the lateral femoral cutaneous nerves is blocked in $95 \%$, but the obturator nerve is almost always spared (Parkinson et al., 1989). Therefore, a 3-in-1 block with the paravascular approach seems difficult to obtain, and, as a consequence, when all three nerves need to be anesthetized a posterior lumbar plexus block or a multitruncular block should be performed. The anterior approach to the femoral nerve is similar for "single shot" or continuous nerve blocks. A femoral nerve block can be obtained with single shot of local anesthetic or by using a continuous catheter technique. The localization of the femoral nerve can be obtained by the use of nerve stimulator or with ultrasound guidance. When using single shot technique, the local anesthetic agent is injected through the needle after location of the nerve with the nerve stimulator. When using continuous catheter techniques, the nerve can be stimulated via the needle through which the catheter is placed, or via both the needle and the catheter itself.

This narrative review summarizes the evidence derived from randomized controlled trials (RCTs) and retrospective analysis, in order to determine the efficacy of continuous femoral nerve block comparing the use of stimulating catheters with non-stimulating catheters for lower-extremity surgery. Furthermore, we explore the adjunctive use of ultrasonography for femoral nerve block. 


\subsection{Anatomy (Gray \& Henry, 1918)}

The Femoral Nerve, the largest branch of the lumbar plexus, arises from the dorsal divisions of the second, third, and fourth lumbar nerves. It descends through the fibers of the Psoas major, emerging from the muscle at the lower part of its lateral border, and passes down between it and the Iliacus, behind the iliac fascia; it then runs beneath the inguinal ligament, into the thigh, and splits into an anterior and a posterior division. At this level it is located lateral and posterior to the femoral artery.

The anterior division of the femoral nerve gives off (Table 1 ):

- Anterior cutaneous branches. The anterior cutaneous branches comprise the intermediate and medial cutaneous nerves

- The intermediate cutaneous nerve pierces the fascia lata (and generally the Sartorius) and divides into two branches which supply the skin as low as the front of the knee. Here they communicate with the medial cutaneous nerve and the infrapatellar branch of the saphenous, to form the patellar plexus.

- The medial cutaneous nerve passes obliquely across the upper part of the sheath of the femoral artery, and divides into two branches, an anterior and a posterior. Before dividing it gives off a few filaments, which supply the integument of the medial side of the thigh, accompanying the long saphenous vein. The anterior branch divides into two branches: one supplies the integument as low down as the medial side of the knee; the other crosses to the lateral side of the patella. The posterior branch descends along the medial border of the Sartorius muscle to the knee, where it pierces the fascia lata, communicates with the saphenous nerve, and gives off several cutaneous branches. It then passes down to supply the integument of the medial side of the leg.

- Muscular branches - The nerve to the Pectineus and the nerve to the Sartorius

The posterior division of the femoral nerve gives off (Table 1):

- The saphenous nerve - the largest cutaneous branch of the femoral nerve. It approaches the femoral artery where this vessel passes beneath the Sartorius, and lies in front of it, behind the aponeurotic covering of the adductor canal, as far as the opening in the lower part of the Adductor magnus. It descends vertically along the medial side of the knee behind the Sartorius, pierces the fascia lata, between the tendons of the Sartorius and Gracilis, and becomes subcutaneous. The nerve then passes along the tibial side of the leg, accompanied by the great saphenous vein, descends behind the medial border of the tibia, and, at the lower third of the leg, divides into two branches: one continues its course along the margin of the tibia, and ends at the ankle; the other passes in front of the ankle, and is distributed to the skin on the medial side of the foot, as far as the ball of the great toe. The saphenous nerve, about the middle of the thigh, gives off a branch which joins the subsartorial plexus. At the medial side of the knee it gives off a large infrapatellar branch, which pierces the Sartorius and fascia lata, and is distributed to the skin in front of the patella. Below the knee, the branches of the saphenous nerve are distributed to the skin of the front and medial side of the leg, communicating with the cutaneous branches of the femoral, or with filaments from the obturator nerve.

- Muscular branches supply the four parts of the Quadriceps femoris. The branch to the Rectus femoris enters the upper part of the muscle, and supplies a filament to the hipjoint. The branch to the Vastus lateralis enters the lower part of the muscle and gives off an articular filament to the knee-joint. The branch to the Vastus medialis enters the 
muscle about its middle, and gives off a filament to the knee-joint. The branches to the Vastus intermedius, two or three in number, enter the muscle about the middle of the thigh and give off filament to the Articularis genu and the knee-joint.

- Articular branches

- articular branch to the hip-joint is derived from the nerve to the Rectus femoris.

- articular branches to the knee-joint are three in number. One is derived from the nerve to the Vastus lateralis, the second derived from the nerve to the Vastus medialis and the third branch is derived from the nerve to the Vastus intermedius.

\begin{tabular}{|l|c|}
\hline \multicolumn{2}{|c|}{ Femoral Branches } \\
\hline $\begin{array}{l}\text { Anterior division } \\
\text { provides sensory innervation } \\
\text { to the skin of the anterior } \\
\text { and medial thigh and motor } \\
\text { innervation to the Sartorius } \\
\text { and Pectineus muscles. }\end{array}$ & $\begin{array}{r}\text { Anterior cutaneous branches } \\
0\end{array}$ \\
$\begin{array}{r}\text { Muscular branches } \\
0\end{array}$ & $\begin{array}{c}\text { medial cutaneous nerves } \\
\text { Posterior division } \\
\text { provides sensory innervation } \\
\text { to the medial part of the } \\
\text { lower leg and motor } \\
\text { innervation to the quadriceps } \\
\text { muscle }\end{array}$ \\
\hline
\end{tabular}

Table 1. Anatomy of femoral nerve

\subsection{Indications}

The femoral nerve block is mainly indicated for the pain control associated with unilateral anterior knee surgery (total knee arthroplasty, ACL). It is also ideal for surgery that involves the hip (femoral fracture repair) or anterior thigh. The block is often combined with a sciatic nerve block or with obturator nerve block if surgery is distal or posterior to the knee join.

\subsection{Contraindications}

- Infection or haematoma In the puncture site

- Local anesthetic allergy

- Lesion of the nerves to be stimulated distal to the puncture site

- Neurological deficit of the leg to be anaesthetised

- $\quad$ Refusal of the procedure by the patient

\section{History of continuous nerve blocks}

The first attempt to practice a continuous peripheral nerve blockade was done by Ansbro in 1946, who described a continuous block of the brachial plexus at a supraclavicular level (Ansbro, 1946). A continuous axillary block was performed in 1977 by Selander in patients who underwent hand surgery. (Selander, 1977). 
The first use of an epidural catheter at the level of the lumbar plexus was reported by Brands and Callanan. Their conclusion was that continuous lumbar plexus blockade reduced administration of opioids and resulted in effective pain relief. (Brands E\& Callanan VI, 1987 as cited in Navas et al., 2005). A continuous sciatic nerve block to relieve pain from ischaemic gangrene of the foot was described in 1984 by Smith et al. (Smith et al, 1984 as cited by Navas et al., 2005).

In order to provide reliable post-operative analgesia and prevent readmission due to failed catheter placement, it was necessary to develop methods to ensure accurate catheter positioning and to prevent catheter dislodgment.

Improvements in techniques and instruments have led to a painless, longer-lasting postoperative analgesia, with reduction of Opioids consumption, better functional recovery, increased patient satisfaction and reduced side-effects. New techniques and devices are increasingly appearing, and catheters are constantly being developed and improved (Navas et al., 2005)

\section{Continuous femoral catheter placement technique (Fig 1- 2)}

The patient should be in the supine position with legs spread slightly apart. After aseptic skin disinfection and sterile draping of the inguinal region, a local anesthetic is injected superficially. The stimulating needle insertion site is immediately below the inguinal crease, 1 to $2 \mathrm{~cm}$ lateral to the femoral artery pulsation. A 50-mm 18-gauge insulated stimulating needle is then connected to the peripheral nerve stimulator (PNS) with an initial current output of 1 $\mathrm{mA}(2 \mathrm{~Hz}, 0.1 \mathrm{~ms})$. The stimulating needle has to be inserted with a $45^{\circ}$ angle and advanced in a cephalad direction until quadriceps femoris muscle contractions were elicited (as evidenced by cephalad patellar movements). The needle position has to be adjusted until quadriceps femoris contractions are still elicited at a current of $0.5 \mathrm{~mA}$ or less. At this point, a 20-gauge catheter is introduced through the needle. The catheter is then advanced for 10 to $15 \mathrm{~cm}$ beyond the needle tip, needle is withdrawn and the catheter has to be secured in place. The local anesthetic of choice, has to be injected slowly through the catheter.

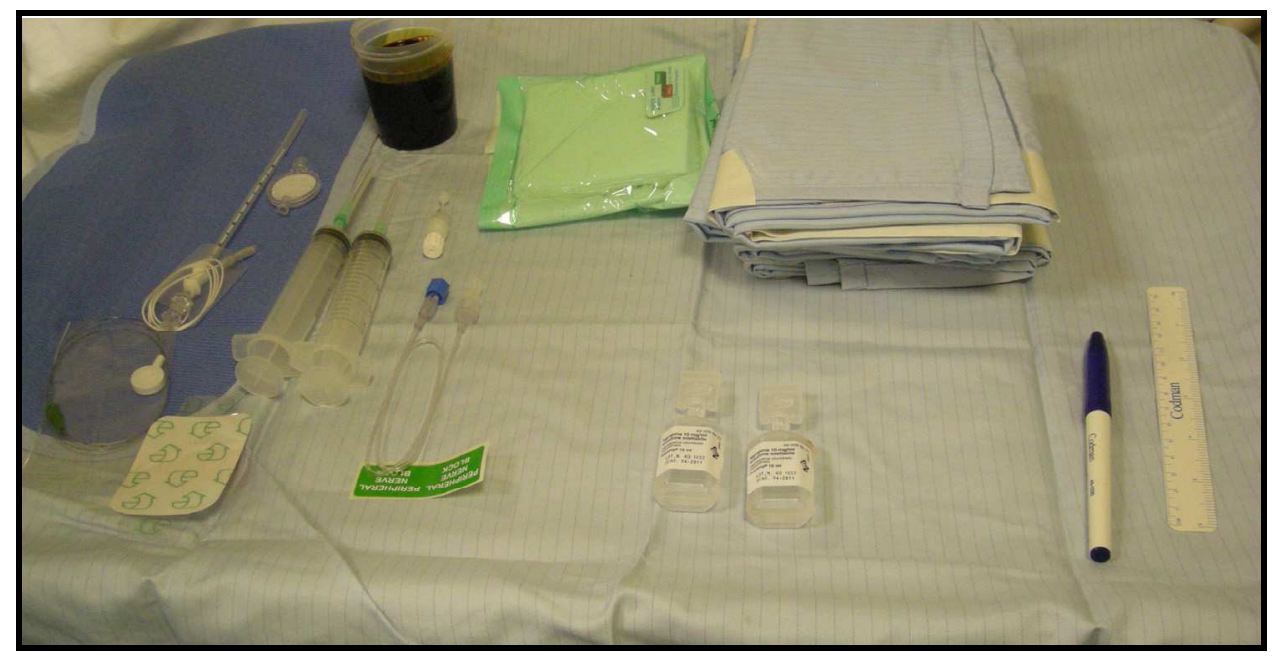

Fig. 1. Equipement 
When stimulating catheter is being used, the catheter has to be connected to the PNS without changing the current output. The catheter is advanced 5 to $15 \mathrm{~cm}$ past the needle tip, and its position is adjusted until quadriceps femoris contractions are still elicited at a current output between 0.4 to $0.5 \mathrm{~mA}$. At this point, the needle is withdrawn and quadriceps contractions are elicited via the catheter again to confirm the final perineural position of the catheter. (Dauri et al., 2007)

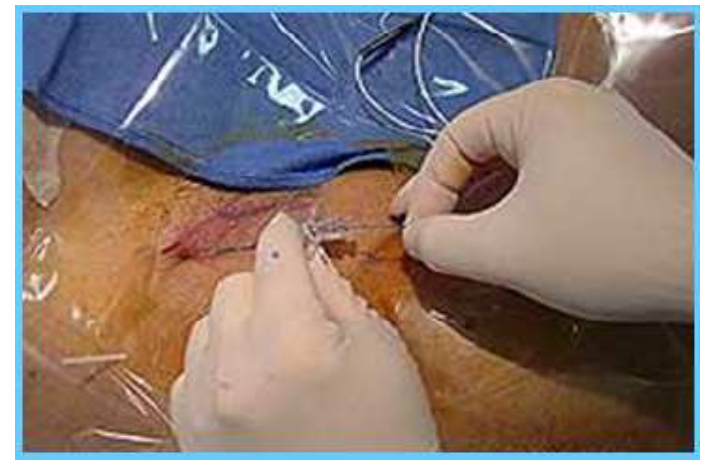

Fig. 2. Catheter placement

\subsection{Local anesthetics}

A number of local anesthetics may be used for femoral nerve blocks. In general, the volume of local anesthetic used to achieve a surgery anesthesia for a femoral nerve block will range from $15-20 \mathrm{ml}$. For 3-in-1 nerve block, the volume ranges from $25-30 \mathrm{ml}$. When postoperative analgesia is required, $0.5 \%$ of long acting anesthetic agents ropivacaine or levobupivacaine is often used. For postoperative analgesia, $1-2 \mathrm{mg} / \mathrm{ml}$ ropivacaine or $0.625-1.25 \mathrm{mg} / \mathrm{ml}$ levobupivacaine are used. The drugs are best administered by PCA pump with a basal rate infusion of 5-8 ml/h and bolus option.

\subsection{Complications}

- Vascular puncture

- Local infection

- Seizures (from systemic injection and local anesthetic toxicity)

- Neural ischemia and/or neural toxicity

- Local anesthetic toxicity:

- CNS: tinnitus, confusion, metallic taste in the mouth

- Cardiac: tachycardia, hypertension, arrhythmia

- Dislocation of the catheter

- Catheter breakage, formation of knots or loops

- Local anesthetic leakage (Gurnaney et al., 2011)

\section{Continuous femoral block versus other techniques}

Many studies were conducted in order to explore the benefits arising from continuous femoral nerve block compared with other analgesic techniques. Some of the studies conclusions are reported below: 
- Continuous peripheral nerve blocks improve postoperative analgesia, patient satisfaction, and rehabilitation compared with IV narcotic therapy for lower extremity procedures (Capdevila et al., 1999; Singelyn et al., 1998; Ganapathy et al., 1999)

- Continuous femoral nerve blocks have been demonstrated to improve the outcome of total knee arthroplasty (capdevila et al., 1999; Chelly et al, 2001)

- Continuous femoral nerve block technique provides similar or better analgesia with fewer undesirable effects than intravenous PCA and the epidural technique during the first $48 \mathrm{~h}$ of postoperative management after total knee arthroplasty and after total hip arthroplasty (Singelyn et al., 1998; Singelyn et al., 1999).

- Outcome with continuous femoral nerve block has shown to be better than "single shot" femoral block and continuous epidural anesthesia. For analgesia after proximal lower limb orthopedic surgery, continuous three-in-one nerve blockade is as effective as epidural analgesia, with fewer side effects (urinary retention, nausea, and risk of spinal subarachnoid hemorrhage in anticoagulated patients) (Capdevila et al., 1999; Singelyn et al 1998)

\section{Correlation between catheter position and the rate of effective sensory and motor blockades}

Continuous femoral nerve block is commonly obtained with a peripheral nerve stimulator connected to a stimulating needle to localize the femoral nerve. The localization of the nerve is then followed by insertion of the catheter through the needle. Studies using blind advancement of femoral catheters indicate that catheter position in relation to the nerve is unpredictable. (Ganapathy et al., 1999; Capdevila et al., 2002) Therefore, even if the initial injection of local anesthetic through the needle produces adequate intraoperative anesthesia/analgesia, subsequent infusion through the catheter may not provide adequate postoperative analgesia. Furthermore, it is difficult to determine the correct catheter's position in order to obtain an effective postoperative analgesia; on the other side the proximity of the catheter to the femoral nerve could guarantee a better analgesia.

Few studies were conducted on the matter:

- Marhofer et al. used MRI scans in order to verify the distribution of local anesthetic. They showed that there is no evidence of cephalad spread of $30 \mathrm{ml}$ of local anaesthetic when a 3-in-1 blockade is performed (Marhofer et al., 2000) .

- Ganapathy et al. used CT scans to verify the catheter position. They observed that only $40 \%$ of catheters are located in an 'ideal' position, defined as catheter-tip position at 2 $\mathrm{cm}$ of the cephalad extremity of the sacroiliac joint or between the sacral promontory and the lateral portion of the vertebral bodies of L4 and L5. (Ganapathy et al., 1999)

- Capdevila et al. used anteroposterior pelvic radiograph to determine the location of the distal tip of the catheter. They showed catheter location in a continuous 3-in- 1 block to be unpredictable. Their conclusion was that during a continuous three-in-one block, the threaded catheter rarely reached the lumbar plexus and that the quality of sensory and motor blockade and initial pain relief depend on the location of the catheter tip under the fascia iliaca. (Capdevila et al., 2002) .

The reported results may highlight the theoretical advantages of using a stimulating catheter to ensure proper perineural catheter placement. The catheter's position could be fixed at a point where the desired motor response is observed at a stimulation intensity that guarantees its proximity to the femoral nerve. 


\section{Aim of the review}

This narrative review summarizes the evidence derived from randomized controlled trials (RCTs) and retrospective analysis, in order to determine the benefits and harm comparing continuous femoral nerve block with stimulating catheters versus non-stimulating catheters for lower-extremity surgery; moreover we will explore the association with adjunctive ultrasonography (US) and stimulating perineural catheters for femoral nerve block.

\section{Methods of searching literature}

We searched PubMed, EMBASE, and the Cochrane Database using the following search terms: "ACL or anterior cruciate ligament" OR "knee arthroplasty" OR "knee surgery" AND "femoral nerve block" OR " peripheral nerve block" OR "regional anesthesia" AND "stimulating catheters" OR "non-stimulating catheters" AND "ultrasonography". Study were included in the review if they were randomized clinical trial (RCTs) and non randomized clinical trial comparing femoral nerve block with stimulating catheters versus non-stimulating catheters for elective knee surgery or RCTs comparing the insertion of stimulating catheters with or without ultrasonographic guidance; limits: English language, human adults. In addition to the systematic search of the bibliographic databases, the reference lists of all retrieved articles were screened for additional relevant trials.

\section{Study description and results (Table 2 )}

An initial search yielded 8 potentially relevant clinical trial that were further examined. Two of these was subsequently excluded because it did not meet the inclusions criteria. A total of 733 patients were investigated: 311 patients with stimulating and 422 with nonstimulating catheters .

Salinas et Al. in 2004 (Salinas et al., 2004) published a prospective comparison of continuous femoral nerve block with nonstimulating catheter placement versus stimulating catheterguided perineural placement, randomizing twenty volunteers; a stimulating catheter was placed on one side and an identical non-stimulating catheter on the contralateral side. Success of femoral block was defined as loss of sensation to cold and pinprick stimuli. Quality of successful block was determined by tolerance to transcutaneous electrical stimulation and force dynamometry of quadriceps strength. Despite the trial shown that block success was $100 \%$ via the stimulating catheters versus $85 \%$ via the nonstimulating catheters, they concluded that there was no statistically significant difference in block success between the two techniques.

Morin et Al. (Morin et al., 2005) in the following year published the results from the comparison between femoral nerve catheters inserted under continuous stimulation and catheters that were placed using the conventional technique of blind advancement in 81 patients undergoing major knee surgery. The aim of his randomized double blind trial was to determine whether accurate catheter positioning under continuous stimulation accelerates the onset of sensory and motor block, improves the quality of postoperative analgesia, and enhances functional recovery. He concluded that with continuous femoral nerve blocks, blind catheter advancement is as effective as the stimulating catheter 
technique with respect to onset time of sensory and motor block as well as for postoperative pain reduction and functional outcome.

A retrospective non randomized study of 419 patients was published in 2005 (Jack et al., 2005) comparing stimulating versus nonstimulating femoral catheter; it demonstrated no differences in term of visual analogue scale score and total morphine consumption with 3 days follow up. The conclusion was that the practical advantages of the stimulating catheter, as reported by previous investigators, were not obvious in this clinical situation.

In 2006 (Hayek et al., 2006) a randomized study was performed to evaluate whether a stimulating catheter allowed the use of lesser amounts of local anesthetics than a nonstimulating catheter concluding that the use of stimulating catheters in continuous femoral nerve blocks for TKA does not offer significant benefits over traditional nonstimulating catheters.

The experience from our department (Dauri et al., 2007) is about the evaluation of the efficacy of stimulating catheter to perform continuous femoral nerve block for anterior cruciate ligament reconstruction; data collection from 70 patient regarded pain scores, adverse effects, and need for supplemental anesthesia and analgesia other than a continuous postoperative infusion of ropivacaine $2 \mathrm{mg} / \mathrm{mL}$ through the continuous femoral nerve catheter set at $7 \mathrm{~mL} / \mathrm{h}$. Data collected shown that although the use of a stimulating catheter was associated with faster onset time for the femoral nerve block and lower additional analgesics postoperatively, the conclusions was that the clinical superiority (analgesia; lateral femoral cutaneous, and obturator nerve block) of stimulating catheters was not evident in this clinical setting.

\begin{tabular}{|c|c|c|c|}
\hline & Study design & Results & Conclusions \\
\hline $\begin{array}{l}\text { Salinas et al., } \\
2004\end{array}$ & 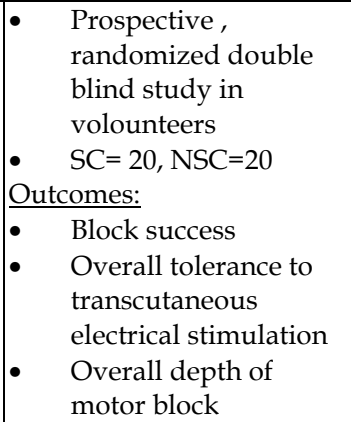 & $\begin{array}{ll}\text { - } & \text { Block success : } \\
\text { - } & \text { SC } 100 \%, \text { NSC } 85 \%(\mathrm{p} 0.07) \\
& \text { Overall tolerance to } \\
& \text { transcutaneous electrical } \\
& \text { stimulation (p 0.009) and } \\
\text { - } & \text { overall depth of motor } \\
\text { block(p 0.03) was } \\
\text { significantly higher in the } \\
\text { stimulating catheter-guided } \\
\text { femoral nerve blocks }\end{array}$ & $\begin{array}{l}\text { There was no } \\
\text { statistically significant } \\
\text { difference in block } \\
\text { success between the } \\
\text { two techniques. } \\
\text { Stimulating catheter- } \\
\text { guided placement } \\
\text { provided an increased } \\
\text { overall quality of } \\
\text { continuous femoral } \\
\text { perineural blockade. }\end{array}$ \\
\hline $\begin{array}{l}\text { Morin et al., } \\
2005\end{array}$ & 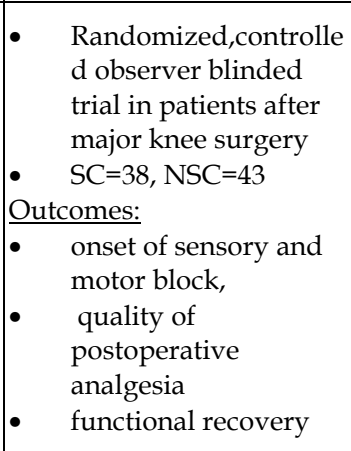 & $\begin{array}{l}\text { onset time of sensory and } \\
\text { motor block similar in both } \\
\text { groups } \\
\text { no differences in the } \\
\text { postoperative IV opioid } \\
\text { consumption, and visual } \\
\text { analog scale pain scores at } \\
\text { rest and movement } \\
\text { No differences in maximal } \\
\text { bending and stretching of the } \\
\text { knee joint during the } 5 \text { days } \\
\text { after surgery. }\end{array}$ & $\begin{array}{l}\text { With continuous } \\
\text { femoral nerve blocks, } \\
\text { blind catheter } \\
\text { advancement is as } \\
\text { effective as the } \\
\text { stimulating catheter } \\
\text { technique with respect } \\
\text { to onset time of } \\
\text { sensory and motor } \\
\text { block, for } \\
\text { postoperative pain } \\
\text { reduction and } \\
\text { functional outcome. }\end{array}$ \\
\hline
\end{tabular}




\begin{tabular}{|c|c|c|c|}
\hline & Study design & Results & Conclusions \\
\hline $\begin{array}{l}\text { Hayek et al., } \\
2006\end{array}$ & $\begin{array}{l}\text { randomized } \\
\text { prospective study of } \\
\text { patients undergoing } \\
\text { TKA } \\
\text { - } \quad \text { SC=19, NSC }=22 \\
\text { Outcomes: } \\
\text { amounts of local } \\
\text { anesthetics } \\
\text { postoperative pain } \\
\text { scores, } \\
\text { opioid use } \\
\text { side effects } \\
\text { acute functional } \\
\text { orthopedic outcomes }\end{array}$ & $\begin{array}{l}\text { no statistically significant } \\
\text { differences in the amount of } \\
\text { ropivacaine administered (MD } \\
-0.6, \mathrm{CI}-2.3 \text { to } 0.6 . \mathrm{P}=0.26) \\
\text { No significant differences } \\
\text { between groups for the } \\
\text { amount of fentanyl dispensed } \\
\text { by the IV patient-controlled } \\
\text { anesthesia } \\
\text { No differences in numeric } \\
\text { pain rating scale scores } \\
\text { No differences in acute } \\
\text { functional orthopedic } \\
\text { outcomes, side effects, or } \\
\text { amounts of oral opioids } \\
\text { consumed. }\end{array}$ & $\begin{array}{l}\text { The use of stimulating } \\
\text { catheters in continuous } \\
\text { femoral nerve blocks } \\
\text { for TKA does not offer } \\
\text { significant benefits over } \\
\text { traditional } \\
\text { nonstimulating } \\
\text { catheters. }\end{array}$ \\
\hline $\begin{array}{l}\text { Dauri et al., } \\
2007\end{array}$ & $\begin{array}{ll}\text { - } & \text { prospective } \\
\text { randomized controlled } \\
\text { trial in patients } \\
\text { undergoing anterior } \\
\text { cruciate ligament } \\
\text { reconstruction } \\
\text { SC }=35, \mathrm{NSC}=35 \\
\text { Outcomes: } \\
\text { pain score } \\
\text { adverse effects } \\
\text { need for supplemental } \\
\text { anesthesia and } \\
\text { analgesia other than a } \\
\text { continuous } \\
\text { postoperative infusion } \\
\text { of ropivacaine } 2 \\
\text { mg/mL set at } 7 \mathrm{~mL} / \mathrm{h} .\end{array}$ & $\begin{array}{l}\text { Onset time was faster in the } \\
\text { SC group (SC: } 6.4 \pm 2.5, \text { NSC: } \\
8.3 \pm 2.9 \text { min, } P \text { 0.006). } \\
\text { No differences in Visual } \\
\text { analog scale. } \\
\text { The number of patient- } \\
\text { controlled regional analgesia } \\
\text { boluses (SC: } 14.6 \pm 12.6 \text {, } \\
\text { NSC:23.2 } \pm 13.6 \mathrm{mg} \text { ropivacaine } \\
2 \mathrm{mg} / \mathrm{mL}, P \_.008 \text { ) as well as } \\
\text { intravenous rescue ketorolac } \\
\text { (SC: } 34.3 \pm 35.7, \text { NSC: } 54 \pm 39.7 \\
\text { mg, } P 0.033 \text { ) administered } \\
\text { were higher in the NSC group. }\end{array}$ & $\begin{array}{l}\text { Although the use of a } \\
\text { stimulating catheter } \\
\text { was associated with } \\
\text { faster onset time for the } \\
\text { femoral nerve block } \\
\text { and lower additional } \\
\text { analgesics } \\
\text { postoperatively, the } \\
\text { clinical superiority } \\
\text { (analgesia; lateral } \\
\text { femoral cutaneous, and } \\
\text { obturator nerve block) } \\
\text { of stimulating catheters } \\
\text { was not evident in this } \\
\text { clinical setting. }\end{array}$ \\
\hline $\begin{array}{l}\text { Barrington et } \\
\text { al., } 2008\end{array}$ & $\begin{array}{ll}\text { - } & \text { randomized, } \\
\text { controlled, double- } \\
\text { blind trial in patient } \\
\text { undergoing TKA } \\
\text { SC=40, NSC }=42 \\
\text { Outcomes: } \\
\text { - } \\
\text { Sensory blockade at } 10 \\
\text { min, } 20 \text { min after } \\
\text { injection of, lidocaine } \\
\text { via femoral catheter } \\
\text { and at postoperative } \\
\text { days 1 (POD 1) and } 2 \\
\text { (POD 2) } \\
\text { Morphine } \\
\text { requirements } \\
\text { pain scores } \\
\text { markers of early } \\
\text { recovery }\end{array}$ & 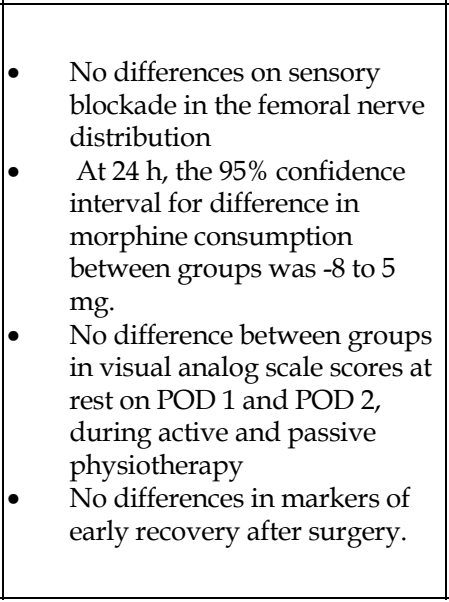 & $\begin{array}{l}\text { In this study, blind } \\
\text { catheter advancement } \\
\text { was as reliable as a SC } \\
\text { technique for } \\
\text { establishing and } \\
\text { maintaining CFNB for } \\
\text { postoperative analgesia } \\
\text { as a part of multimodal } \\
\text { analgesia technique } \\
\text { after TKA. }\end{array}$ \\
\hline
\end{tabular}

Table 2. Study included in analysis $(\mathrm{SC}=$ stimulating catheter, $\mathrm{NSC}=$ non stimulating catheter, $\mathrm{TKA}=$ Total knee arthroplasty, $\mathrm{CFNB}=$ continuous femoral nerve block) 
Recently, a randomized clinical trial (Barrington et al., 2008) compared a stimulating catheter with a nonstimulating catheter technique for institution of continuous femoral nerve block and its effects on quality of analgesia after total knee arthroplasty performed under general anesthesia in 82 patients. Patients were randomized to have continuous femoral nerve block instituted using either a non-stimulating or a stimulating catheter technique. There were no differences in term of included morphine requirements, pain scores, and markers of early recovery. There was an increase in procedural time required for insertion of a SC compared with a NSC (10 and $6 \mathrm{~min}$, respectively); however, this is of debatable clinical significance.

They concluded that blind catheter advancement was as reliable as a stimulating catheter technique for establishing and maintaining continuous femoral nerve block for postoperative analgesia as a part of multimodal analgesia technique after total knee arthroplasty.

In summary, although advantageous from a theoretical standpoint and in experimental designs (Salinas et al., 2004), randomized controlled trials in the clinical environment have yielded limited evidence to justify use of stimulating catheters for continuous femoral nerve block after knee surgery. The increased cost and need for additional catheter adjustments compared with nonstimulating catheter also make it hard to justify their use in this clinical setting.

\section{Discussion: Focus on}

Postoperative pain after major knee surgery is a major concern. It is severe in $60 \%$ of patients and moderate in another 30\% (Singelyn et al., 1998; 2000). Pain has a major impact on patient satisfaction and postoperative well-being. In addition, pain impairs early intensive physical therapy and rehabilitation, probably the most influential factor for good postoperative knee rehabilitation (Singelyn \& Gouverneur, 2000; Capdevila et al., 1999).

Continuous peripheral nerve blocks offer the potential benefits of extended postoperative analgesia, few side effects, improved patient satisfaction, and accelerated functional recovery after major knee surgery (Liu \& Salinas, 2003); for this reason continuous femoral nerve block is often used to provide postoperative analgesia in this clinical setting (Singelyn et al.,1998; Capdevila et al., 1999)

\subsection{Catheter tip}

When performing a continuous femoral nerve block, efforts are made to place the catheter close to the nerve to achieve effective perioperative analgesia. Traditionally, catheter placement is performed through a stimulating needle, followed by injection of the local anesthetic and then blind advancement of the peripheral catheter beyond the needle tip. Secondary analgesic block failure rate (failure of a catheter to produce postoperative analgesia after having provided sufficient intraoperative analgesia with the bolus administration) with this technique ranges from 10\% (Grant et al., 2001; Chelly \& Casati, 2003) up to $40 \%$ (Salinas, 2003). This may be explained by the fact that the catheter can curl away from the needle during uncontrolled advancement (Salinas 2003). Correct catheter placement is confirmed by testing for a clinical effect of satisfactory analgesia or by sensory modality testing within the desired sensory distribution after injection of the local anesthetic. However, in case of insufficient block, the catheter cannot be further redirected. 
The rational for using stimulating catheters, introduced in 1999 (Boezaart et al., 1999) is based on the assumption that catheter tips are directed close to nerves; in fact it provide the possibility to verify the position the catheter takes during advancement through the cannula. A study performed by Pham Dang et al (Pham Dang et al., 2003) concluded that the ability to electrostimulate nerves using an in situ catheter increases success rate in catheter placement for continuous peripheral nerve blocks. However, they were surprised to find that the amperage required to elicit motor responses is higher with the stimulating catheter than with the introducer needle. In a study performed by Morin et al (Morin et al., 2005), the authors did not find a relationship between the current that had to be applied via the stimulating catheter to evoke a motor response and any of the variables determined to judge the success of the catheter positioning. Viewing this works, doubts may arise regarding the reliability of stimulating catheter to elucidate motor contruction and to determine correct catheter positioning. Furthermore, A stimulation current $0.5 \mathrm{~mA}$ or less is considered safe in order to avoid nerve injury and to deliver adequate stimulus to provoke a motor response. A stady performed by Bigeleisen et al (Bigeleisen et al., 2009) suggest that stimulation currents of more than 0.2 and no more than $0.5 \mathrm{~mA}$ could not rule out an intraneural position of the needle or catheter tip. Therefore, even with the use of low stimulation (0.2-0.5 $\mathrm{mA}$ ) the tip of the stimulating catheters are not ascertained to be in the vicinity of the nerve of might be inside the nerve.

Placement of the catheter tip should ideally be as close as possible to the nerve to attain the minimal blocking concentration that will block the fibers responsible for transmission of painful stimuli. From a practical point, use of larger volumes may permit more successful blocks when nerves are less than ideally localized. This concept is expressed also by Pham Dang et al. (Pham Dang et al., 2009) affirming that interpretation of their data suggests that the failure of previous studies to show a superiority of stimulating catheters has perhaps been masked by methodological problems in previous investigations on the subject. In fact in their study, stimulating catheters seem to provide early analgesia within the femoral nerve distribution using low-dose initial bolus and subsequent low-volume infusion. Small doses of local anesthetics suffice if a catheter is correctly placed next the femoral nerve and that pain from unblocked obturator and sciatic nerves should be treated specifically (Pham Dang 2009).

Moreover, use of larger volumes of local anesthetics may potentially increase the risk of systemic toxicity and potentially increase motor block (Borgeat et al., 2001; Bergman et al., 2000).

More importantly, minimal motor weakness is desired for continuous femoral analgesia after total knee arthroplasty, because excessive quadriceps motor block may impair active knee extension required for rehabilitation protocols and potentially delay achievement of predetermined functional physical therapy goals. To better ascertain the difference between a well placed and a poorly placed catheter, one should use smaller amounts of local anesthetics. Hayek et al. (Hayek et al., 2006), analyzed data regarding the total amount of local anesthetic used in patient treated with stimulating catheter versus nonstimulating group founding no statistically significant differences in the amount of ropivacaine administered .

The question arises whether nerve proximity is really needed for the femoral nerve to be blocked effectively in routine clinical use. Several reasons argue against this necessity, particularly when larger volumes $(40 \mathrm{ml})$ of local anaesthetic are used. Firstly, anatomical review suggests that, once the iliac fascia is penetrated, there are no relevant diffusion barriers for local anaesthetics. Secondly, catheters threaded $16-20 \mathrm{~cm}$ from the inguinal level radiographically deviated in $77 \%$ of cases but were as effective in motor blockade of the 
femoral nerve, and only marginally less effective in sensory blockade of the femoral nerve, compared with radiographically well placed catheters (Capdevila et al., 2002). Thirdly, iliac fascia blocks performed without any nerve stimulation are as effective as femoral nerve blocks, in both children (Dalens et al.,1989) and adults (Capdevila et al., 1998), suggesting no clinically meaningful reason for placing catheter tips in close proximity to the femoral nerve. For these reasons, Birbaum affirmed that well designed studies should to be done to prove the superiority of stimulating catheters, but not for the femoral nerve (Birnbaum \& Volk., 2006).

However, without direct visualization, catheter positions corresponding to the various stimulating tip-to-nerve distances could only be inferred on the basis of the neurostimulation recently developed by Johnson et al. (Jonson et al., 2007).

Another common problem to underling is the lack of control of the pain transmitted by the unblocked obturator nerve in all studies (Morin et al., 2005; Barrington et al., 2008) and the unblocked sciatic nerve in 2 studies (Morin et al., 2005; Hayek et al., 2006). These unblocked nerves constitute major confounding factors during assessment of the femoral block based on pain scores, given that the knee is innervated principally by the femoral, obturator, and sciatic nerves. In contrast to these studies, ours used a low dose of ropivacaine $(0.2 \%)$ for initiation and maintenance of femoral nerve block and eliminated pain from obturator and sciatic nerves by blocking them.(Pham Dang et al., 2009).

It is conceivable that clinicians with less experience might find that the ability to verify accuracy of catheter placement with the stimulating catheter system improves their clinical outcomes. However the introduction of the stimulating catheter requires more expertise than introduction of the non-stimulating catheter. Placing the catheter to give good contractions often involves extra manipulation, reintroduction of the needle, or both. Thus, it would not (necessarily) expect the stimulating catheter to give better results in inexperienced hands.

\subsection{Effect on neurostimulation of injectates used for perineural space expansion}

A randomized clinical trial (Pham Dang et al., 2009) clinically assessed the electrophysiologic effect of dextrose $5 \%$ in water and of normal saline used for expansion of the perineural space before placing a stimulating catheter. They questioned if higher current was required with normal saline but not with dextrose $5 \%$ in water, as has been observed experimentally. This was a prospective randomized double-blind study of ASA I to II patients scheduled for total knee replacement. Patients were randomly assigned to receive unidentified injectate dextrose $5 \%$ in water $(n=25)$ or normal saline $(n=25)$. The primary outcome was the minimal intensity of stimulation (MIS) recorded before and after 2 and $5 \mathrm{~mL}$ of study injectates were flushed through the needle before placing a stimulating catheter for continuous femoral and sciatic nerve blocks. Secondary outcomes included, among other parameters, minimal intensity of stimulation recorded during placement of stimulating catheters.

Analysis of the primary outcome using a between-group comparison showed that minimal intensity of stimulation recorded during electrostimulation via the needle was significantly higher after normal saline than after dextrose $5 \%$ in water in all blocks and at each volume of injectate. This presumably reflects the electrophysiologic properties of normal saline versus dextrose $5 \%$ in water given the absence of difference between groups with all other parameters assessed in this study. To conclude, the use of normal saline for expanding the perineural space led to increased intensity for nerve electrostimulation, which may lead to potential errors when electrolocating the nerve. Dextrose $5 \%$ in water seemed to be a superior medium for perineural space expansion, which is in agreement with the animal and clinical studies of Tsui et al.(Tsui et al., 2005). 


\subsection{An alternative: Ultrasonographic guidance}

Continuous femoral nerve blocks, have recently evolved towards being the gold standard for acute pain therapy after major reconstructive knee surgery, including total knee arthroplasty and certain techniques for anterior cruciate ligament reconstruction. As shown previously, accurate placement of femoral nerve catheters in close proximity to the femoral nerve, allows for a therapy with low infusion rates and minimal boluses, thus increasing its effectiveness and allowing for prolonged analgesia (48-72hours) with small portable disposable pumps in the outpatient setting. Neuro-stimulation and stimulating catheters, were the basis for perfecting continuous femoral blocks. While usually a simple technique, with minimal risks, occasionally, even in experienced hands, stimulating catheters present several shortcomings: lack of placement time consistency, increased costs, lack of direct visualization of local anesthetic spread, variability in stimulating catheter design and quality, uncertainty about nerve stimulation endpoints ( Hayek, 2006; Jack et al., 2005; Morin et al., 2005; Salinas et al., 2004; Birnbaum et al., 2007).

An alternative for assisting with correct catheter placement is ultrasonographic guidance (Fig. 3- 4- 5).

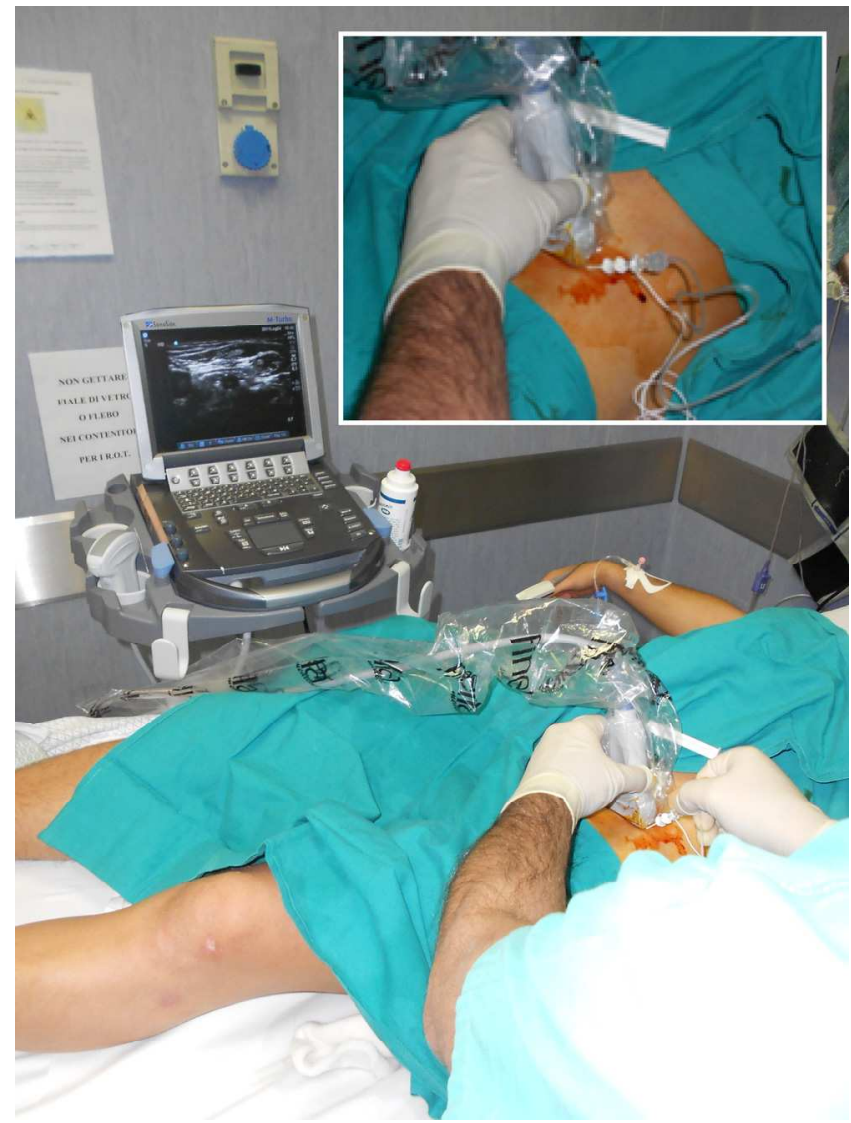

Fig. 3. Ultrasound-guided femoral nerve block: in plane approach 


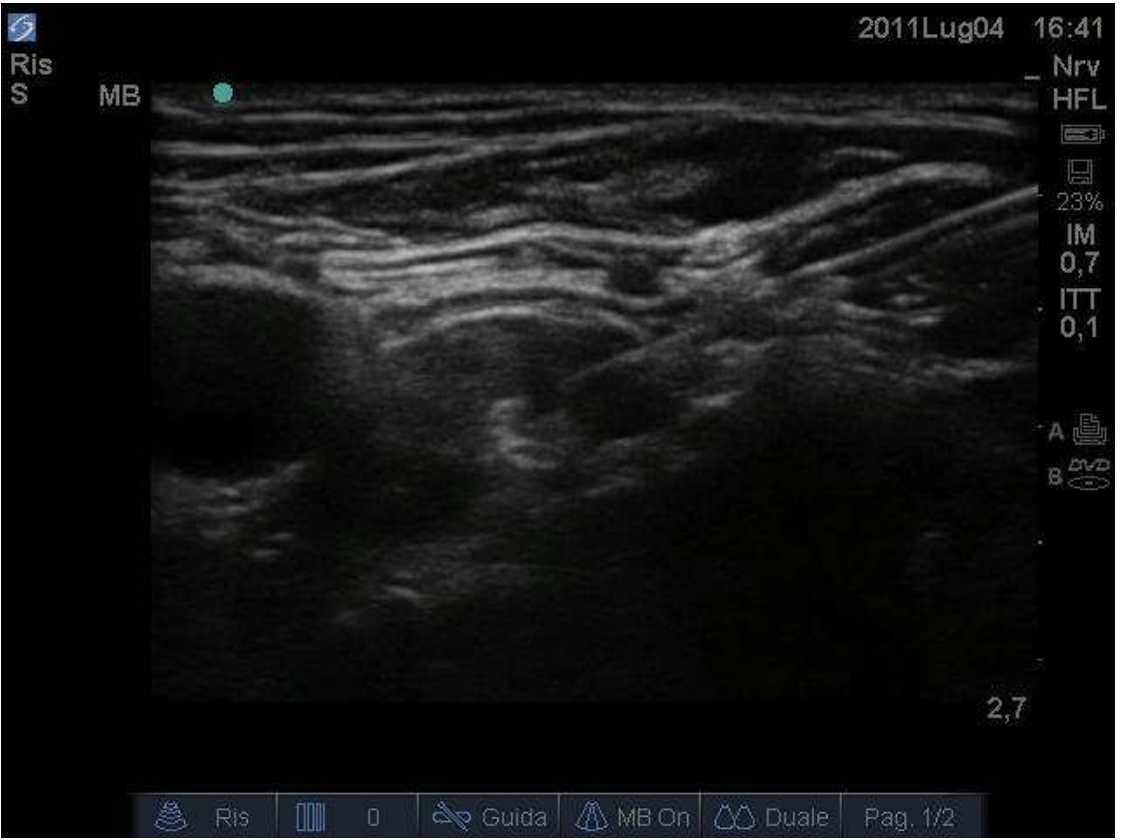

Fig. 4. Ultrasound guided femoral nerve block: needle insertion

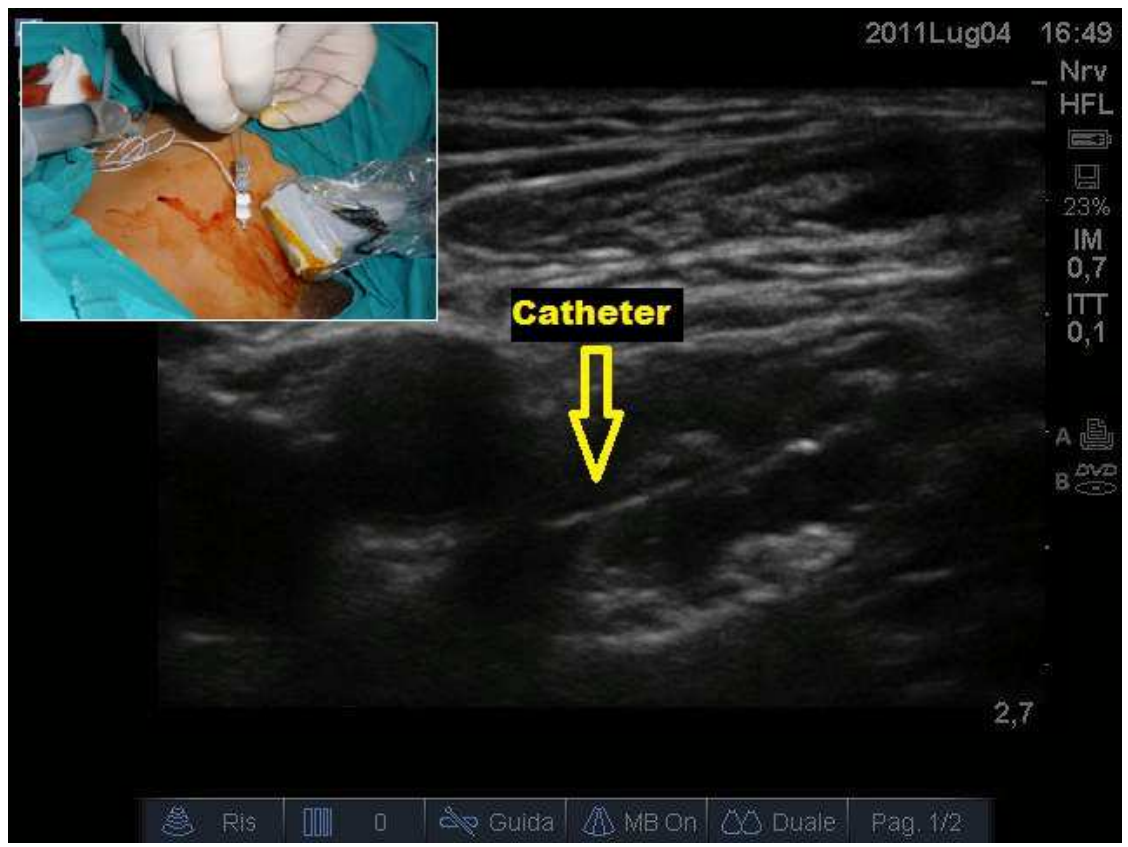

Fig. 5. Ultrasound guided femoral nerve block: catheter insertion 
Ultrasound-guided regional anesthesia is an evolving field and its use has gained enormous popularity in the last 10 years. In one investigation, the onset of sensory blockade with ultrasound guidance was significantly shorter and the quality of sensory block significantly better compared with the nerve stimulator needle-assisted application of local anesthetic (Marhofer et al., 1997). Addition of ultrasound guidance to nerve stimulation could offer the benefits of rapid localization and visualization of local anesthetic spread, at the cost of several disadvantages: need for multiple assistants, increased time and cost; moreover the tip position can suggest proximity even though sufficient nerve stimulation is not achieved, injection of local anaesthetic usually produces a clinically effective block.

Other authors have reported both increased block density and lower anesthetic dose requirements with US-guided techniques when compared with conventional techniques using nerve stimulators (Marhofer, 1997-1998).

Mariano et al. (Mariano et al., 2009) performed a study were patients receiving a femoral perineural catheter for knee surgery were randomly assigned to either ultrasound guidance with a nonstimulating catheter or electrostimulation guidance with a stimulating catheter. The primary outcome was the catheter placement procedure time (minutes) starting when the ultrasound transducer (ultrasound group) or catheter insertion needle (electrostimulator group) first touched the patient and ending when the catheter insertion needle was removed after catheter insertion. He concluded that for femoral perineural catheter placement, an ultrasound-guided technique decreases the procedure time compared with nerve electrostimulation alone while maintaining a similar success rate. Furthermore, patients in the ultrasound group reported less procedure-related pain during perineural catheter placement and had fewer inadvertent vascular punctures (20\% less).

It is possible that using a combination of both approaches may offer additional benefits over either technique alone for brachial plexus perineural catheters (Mariano et al., 2009;Fredricksonet al., 2008). For continuous femoral nerve block the needle is inserted at the level of the inguinal crease along the long axis of the ultrasound probe. The needle shaft and needle tip are clearly visible with this approach during advancement of the needle toward the femoral nerve. Once the needle pierces the fascia iliaca lateral to the nerve, the needle tip is advanced 2 to $3 \mathrm{~mm}$ toward the nerve. This is contrary to the common method of placing the needle tip in close proximity to the nerve. At this point, $5 \mathrm{~mL}$ of dextrose $5 \%$ solution is injected to expand the perineural space, and electrical stimulation conforms a quadriceps or patellar twitch. The position of the needle in conjunction with the injected dextrose provides a path for catheter advancement toward the nerve and the catheter tip to lie in close approximation to the nerve. Had the needle tip initially been placed next to the femoral nerve, the catheter would have advanced medially past the nerve.

Another method to possibly improve catheter advancement is slight withdrawal of the catheter guide wire by 1 to $2 \mathrm{~cm}$ from the tip. This will provide more flexibility to the catheter tip but stiffness to the remainder of the catheter during advancement. This may further decrease the likelihood of catheter advancement away from the tract formed by the injected dextrose solution, thereby improving the ease of catheter insertion (Niazi et al., 2009). To date, however, the need for electro-stimulation in addition to ultrasound guidance remains controversial, especially for lower extremity perineural catheter placement (Chan et al., 2007; Walker \& Roberts, 2007; Beach et al., 2006; Gürkan et al., 2008; Dingemans et al., 2007).

Moreover combining ultrasound with electro-stimulation does negate any cost advantages attributed to ultrasound guidance alone (Sandhu et al., 2004). 


\section{Conclusions}

Randomized controlled trials in the clinical environment have yielded limited evidence to justify use of stimulating catheters for continuous femoral nerve block after knee surgery. It can be affirmed that failure of previous studies to show a superiority of stimulating catheters has perhaps been masked by methodological problems, above all regarding the dose and volume of local anesthetics used. However ultrasound guidance offer a safe and cost/effective technique for femoral catheter placement.

\section{Future directions}

It is important to design future trials in a consistent manner to make studies comparable and to enable a standard quantitative meta-analysis. Future study designs need to account for differences between the primary anesthetic block (bolus or a relatively large mass of concentrated local anesthetic via either the needle or catheter, typically with a long-acting agent) and the secondary analgesic block (infusion of a dilute local anesthetic). Injection of long-acting local anesthetic as the primary block renders interpretation of the secondary analgesic infusion difficult if not impossible for the first 12 to $24 \mathrm{hrs}$ as the residual analgesic effects of the primary block may still be effective.

\section{References}

Ansbro P. A method of continuous brachial plexus block. American Journal of Surgery 1946; 121: $716-722$

Barrington MJ, Olive DJ, McCutcheon CA, Scarff C, Said S, Kluger R, et al. Stimulating catheters for continuous femoral blockade after total knee arthroplasty: a randomized, controlled, double blind trial. Anesth Analg. 2008;106:1316Y1321.

Beach ML, Sites BD, Gallagher JD. Use of a nerve stimulator does not improve the efficacy of ultrasound-guided supraclavicular nerve blocks. J Clin Anesth 2006; 18:580-584.

Bergman BD, Hebl JR, Kent J, Horlocker TT. Neurologic complications of 405 consecutive continuous axillary catheters. Anesth Analg 2000;96:247-252.

Bigeleisen P.E, Moayeri N, Groen G.J. Extraneural versus Intraneural Stimulation Thresholds during Ultrasound-guided Supraclavicular Block. Anesthesiology 2009; 110:1235-43

Birnbaum J et al. "Electrical nerve stimualtion for plexus and nerve blocks" Anaesthesist. 2007 Nov; 56(11): 1156-62 .

Birnbaum J., Volk T. Use of a stimulating catheter for femoral nerve block. British Journal of Anaesthesia 96 (1): 139-42 (2006)

Boezaart AP, de Beer JF, duToit C, van Rooyen KA. New technique of continuous interscalene nerve block. Can J Anaesth 1999;46:275-81.

Borgeat A, Ekatodramis G, Kalberer F, Benz C. Acute and nonacute complications associated with interscalene block: A prospective study. Anesthesiology 2001;95:875-880.

Capdevila X, Barthelet $Y$, Biboulet $P$, et al. Effects of perioperative analgesic technique on the surgical outcome and duration of rehabilitation after major knee surgery. Anesthesiology 1999; 91:8-15.

Capdevila X, Biboulet P, Bouregba M, Barthelet $Y$, Rubenovitch J, d'Athis F. Comparison of the three-in-one and fascia iliaca compartment blocks in adults: clinical and radiographic analysis. Anesth Analg 1998; 86: 1039-44. 
Capdevila X, Biboulet P, Morau D et al. Continuous three-inone block for postoperative pain after lower limb orthopedic surgery: where do the catheters go? Anesth Analg 2002; 94: 1001-6

Chan VW, Perlas A, McCartney CJ, Brull R, Xu D, Abbas S. Ultrasound guidance improves success rate of axillary brachial plexus block. Can J Anaesth 2007; 54:176-182..9,26-29.

Chelly JE, Casati A. Are nonstimulating catheters really inappropriate for continuous nerve block techniques? Reg Anesth Pain Med 2003;28:483-5.

Chelly JE, Greger J, Gebhard R et al. Continuous femoral blocks improve recovery and outcome of patients undergoing total knee arthroplasty. J Arthroplasty 2001; 16: 436-45.

Dalens B, Vanneuville G, Tanguy A. Comparison of the fascia iliaca compartment block with the 3-in-1 block in children. Anesth Analg 1989; 69: 705-13

Dauri M, Sidiropoulou T, Fabbi E, Giannelli M, Faria S, Mariani P, Sabato AF. Efficacy of continuous femoral nerve block with stimulating catheters versus nonstimulating catheters for anterior cruciate ligament reconstruction. Reg Anesth Pain Med. 2007 Jul-Aug;32(4):282-7.

Dingemans E, Williams SR, Arcand G, et al. Neurostimulation in ultrasound-guided infraclavicular block: a prospective randomized trial. Anesth Analg 2007; 104:1275-1280.

Fredrickson MJ, Ball CM, Dalgleish AJ. Successful continuous interscalene analgesia for ambulatory shoulder surgery in a private practice setting. Reg Anesth Pain Med 2008; 33:122-128.

Ganapathy S, Wasserman RA, Watson JT, et al. Modified continuous femoral three-in-one block for postoperative pain after total knee arthroplasty. Anesth Analg 1999;89:1197-202

Grant SA, Nielsen KC, Greengrass RA, et al. Continuous peripheral nerve block for ambulatory surgery. Reg Anesth Pain Med 2001;26:209-14.

Gray, Henry. Anatomy of the Human Body. Philadelphia: Lea E Febiger, 1918; Bartleby.com, 200.

Gürkan Y, Acar S, Solak M, Toker K. Comparison of nerve stimulation vs. ultrasound-guided lateral sagittal infraclavicular block. Acta Anaesthesiol Scand 2008; 52:851-855.

Gurnaney H, Kraemer FW, Ganesh A. Dermabond decreases pericatheter local anesthetic leakage after continuous perineural infusions. Anesth Analg. 2011 Jul;113(1):206.

Hayek SM, Ritchey RM, Sessler D, Helfand R, Samuel S, Xu M, Beven M, Bourdakos D, Barsoum W, Brooks P. Continuous femoral nerve analgesia after unilateral total knee arthroplasty: stimulating versus nonstimulating catheters. Anesth Analg. 2006 Dec;103(6):1565-70.

Jack NT, Liem EB, Vonhögen LH. Use of a stimulating catheter for total knee replacement surgery: preliminary results. Br J Anaesth.2005 Aug;95(2):250-4. Epub 2005 May 27.

Johnson CR, Barr RC, Klein SM. A computer model of electrical stimulation of peripheral nerves in regional anesthesia. Anesthesiology. 2007;106:323Y330.

Liu SS, Salinas FV. Continuous plexus and peripheral nerve blocks for postoperative analgesia. Anesth Analg 2003;96:263-72.

Marhofer P, Nael C, Sitwohl C et al. Magnetic resonance imaging of the distribution of local anesthetic during the three-in-one block. Anesth Analg 2000; 90: 119-24.

Marhofer P, Schrogendorfer K, Koinig H, et al. Ultrasonographic guidance improves sensory block and onset time of three-in-one blocks. Anesth Analg 1997;85:854-7.

Mariano ER, Afra R, Loland VJ, et al. Continuous interscalene brachial plexus block via an ultrasound-guided posterior approach: a randomized, triple-masked, placebocontrolled study. Anesth Analg 2009; 108:1688-1694. 
Mariano ER, Loland VJ, Sandhu NS, Bellars RH, Bishop ML, Afra R, Ball ST, Meyer RS, Maldonado RC, Ilfeld BM. Ultrasound guidance versus electrical stimulation for femoral perineural catheter insertion. J Ultrasound Med. 2009 Nov;28(11):1453-60.

Morin AM, Eberhart LH, Behnke HK, Wagner S, Koch T, Wolf U, Nau W, Kill C, Geldner G, Wulf $\mathrm{H}$. Does femoral nerve catheter placement with stimulating catheters improve effective placement? A randomized, controlled, and observer-blinded trial. Anesth Analg. 2005 May;100(5):1503-10.

Navas A.M, Gutieirrez T.V, Moreno M.E. Continuous peripheral nerve blockade in lower extremity surgery. Acta Anaesthesiol Scand 2005; 49: 1048-1055

Niazi AU, Prasad A, Ramlogan R, Chan VW. Methods to ease placement of stimulating catheters during in-plane ultrasound-guided femoral nerve block. Reg Anesth Pain Med. 2009 Jul-Aug;34(4):380-1.

Parkinson SK, Mueller JB, Little WL, Bailey SL. Extent of blockade with various approaches to the lumbar plexus. Anesth Analg 1989;68:243-248.

Pham-Dang C., Kick o, Collet T, et al. Continuous peripheral nerve blocks with stimulating catheters. Reg Anesth Pain Med 2003;28:83-88.

Pham Dang C, Difalco C, Guilley J, Venet G, Hauet P, Lejus C. Various possible positions of conventional catheters around the femoral nerve revealed by neurostimulation. Reg Anesth Pain Med. 2009 Jul-Aug;34(4):285-9.

Pham Dang C, Lelong A, Guilley J, Nguyen JM, Volteau C, Venet G, Perrier C, Lejus C, Blanloeil Y. Effect on neurostimulation of injectates used for perineural space expansion before placement of a stimulating catheter: normal saline versus dextrose 5\% in water.Reg Anesth Pain Med. 2009 Sep-Oct;34(5):398-403.

Salinas FV, Neal JM, Sueda LA, Kopacz DJ, Liu SS. Prospective comparison of continuous femoral nerve block with nonstimulating catheter placement versus stimulating catheter-guided perineural placement in volunteers. Reg Anesth Pain Med. 2004 May-Jun;29(3):212-20

Salinas FV. Location, location, location: continuous peripheral nerve blocks and stimulating catheters. Reg Anesth Pain Med 2003;28:79-82.

Sandhu NS, Sidhu DS, Capan LM. The cost comparison of infraclavicular brachial plexus block by nerve stimulator and ultrasound guidance. Anesth Analg 2004; 98:267-268.

Selander D. Catheter technique in axillary block. Acta Anaesth Scand 1977;21:324-329.

Singelyn F, Deyaert M, Pendeville E et al. Effects of intravenous patient-controlled analgesia with morphine, continuous epidural analgesia and continuous three-in-one block on postoperative pain and knee rehabilitation after unilateraltotal knee arthroplasty. Anesth Analg 1998; 87: 88-92.

Singelyn F, Gouverneur JM. Postoperative analgesia after total hip arthroplasty: i.v. PCA with morphine, patientcontrolled epidural analgesia, or continuous ' 3 -in-1' block?: a prospective evaluation by our acute pain service in more han 1,300 patients. J Clin Anesth 1999; 11: 550-4.

Singelyn FJ, Gouverneur JM. Extended "three-in-one" block after total knee arthroplasty: continuous versus patient-controlled techniques. Anesth Analg 2000;91:176-80.).

Tsui BC, Kropelin B, Ganapathy S, Finucane B. Dextrose 5\% in water: fluid medium maintaining electrical stimulation of peripheral nerve during stimulating catheter placement. Acta Anaesthesiol Scand. 2005;49:1562Y1565.

Walker A, Roberts S. Stimulating catheters: a thing of the past? Anesth Analg 2007; 104:1001-1002.

Winnie AP, Ramamurthy S, Durrani Z. The inguinal paravascular technique of lumbar plexus anesthesia: The "3 in 1" block. Anesth Analg 1973;52:989-996. 


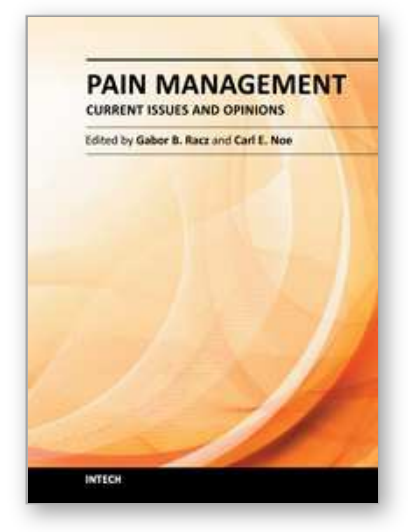

\author{
Pain Management - Current Issues and Opinions \\ Edited by Dr. Gabor Racz
}

ISBN 978-953-307-813-7

Hard cover, 554 pages

Publisher InTech

Published online 18, January, 2012

Published in print edition January, 2012

Pain Management - Current Issues and Opinions is written by international experts who cover a number of topics about current pain management problems, and gives the reader a glimpse into the future of pain treatment. Several chapters report original research, while others summarize clinical information with specific treatment options. The international mix of authors reflects the "casting of a broad net" to recruit authors on the cutting edge of their area of interest. Pain Management - Current Issues and Opinions is a must read for the up-to-date pain clinician.

\title{
How to reference
}

In order to correctly reference this scholarly work, feel free to copy and paste the following:

Mario Dauri, Ludovica Celidonio, Sarit Nahmias, Eleonora Fabbi, Filadelfo Coniglione and Maria Beatrice Silvi (2012). Efficacy of Continuous Femoral Nerve Block with Stimulating Catheters Versus Nonstimulating Catheters - A Systematic-Narrative Review, Pain Management - Current Issues and Opinions, Dr. Gabor Racz (Ed.), ISBN: 978-953-307-813-7, InTech, Available from: http://www.intechopen.com/books/pain-managementcurrent-issues-and-opinions/efficacy-of-continuous-femoral-nerve-block-with-stimulating-catheters-versusnonstimulating-catheter

\section{INTECH}

open science | open minds

\section{InTech Europe}

University Campus STeP Ri

Slavka Krautzeka 83/A

51000 Rijeka, Croatia

Phone: +385 (51) 770447

Fax: +385 (51) 686166

www.intechopen.com

\section{InTech China}

Unit 405, Office Block, Hotel Equatorial Shanghai

No.65, Yan An Road (West), Shanghai, 200040, China

中国上海市延安西路65号上海国际贵都大饭店办公楼405单元

Phone: +86-21-62489820

Fax: +86-21-62489821 
(C) 2012 The Author(s). Licensee IntechOpen. This is an open access article distributed under the terms of the Creative Commons Attribution 3.0 License, which permits unrestricted use, distribution, and reproduction in any medium, provided the original work is properly cited. 